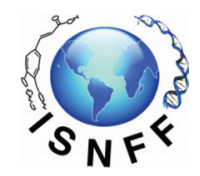

\title{
Should the in vitro colorimetric assays in antioxidant and lipid oxidation evaluation be abandoned? A critical review focusing on bioactive molecule screening assays in in vitro and in vivo models
}

\author{
Fereidoon Shahidi* and JuDong Yeo
}

\author{
Department of Biochemistry, Memorial University of Newfoundland, St. John's, NL, Canada A1B 3X9 \\ ${ }^{*}$ Corresponding author: Department of Biochemistry, Memorial University of Newfoundland, St. John's, NL, Canada A1B 3X9. Tel: +1 \\ 709864 8552; E-mail: fshahidi@mun.ca
}

DOI: $10.31665 /$ JFB. 2020.9215

Received: March 18, 2020; Revised received \& accepted: March 31, 2020

Citation: Shahidi, F., and Yeo, J.D. (2020). Should the in vitro colorimetric assays in antioxidant and lipid oxidation evaluation be abandoned? A critical review focusing on bioactive molecule screening assays in in vitro and in vivo models. J. Food Bioact. 9: 23-35.

\begin{abstract}
Increasing evidence has proven the potent antioxidative effectiveness of bioactives in natural products for preventing/suppressing chronic diseases. In this connection, the development of efficient methods that are suitable to screen bioactives in vitro and in vivo tests has taken place. Thus, a variety of assays have been used in the extraction of bioactives, testing of their antioxidant potential in both in vitro and in vivo model, and evaluating lipid oxidation are comprehensively discussed here. This review mainly focuses on the principle and the use of individual assays in both in vitro and in vivo models. Given that induvial assays have pros and cons due to the discrepancy in the reaction environment and applied biological system, application to the various assays in order to complement the drawbacks of each assay is highly recommended to obtain reasonable information from experimental trials.
\end{abstract}

Keywords: Bioactives; Antioxidant activity; Extraction; Lipid oxidation; Cell line; In vivo; Animal model.

\section{Introduction}

Antioxidants play a crucial role in both food and biological systems by retarding oxidative processes and providing health-promoting activities. Different antioxidant mechanisms are involved in preventing lipid oxidation such as radical scavenging potential through hydrogen atom transfer (HAT) and single electron transfer (SET) as well as metal chelation. These mechanisms contribute to the stabilization of free radicals generated from lipid oxidation as well as preventing the initiation of autoxidation by chelating prooxidative transition metal ions. In biological systems, antioxidants are responsible for inhibiting chronic diseases including cancer, inflammatory diseases, diabetes, cardiovascular and neurodegenerative disorders (Shahidi and Yeo, 2018). Moreover, bioactives in foods exhibit strong inhibitory effects against the incidence of Parkinson's and Alzheimer's diseases (Shahidi and Yeo, 2018).

A variety of analytical methods have been developed and used to measure antioxidant potential of bioactive compounds including ferrous-ion chelating activity (Carter, 1971), lipid peroxidation inhibition assay (Daker et al., 2008), deoxyribose assay (Chen et al., 2005), and superoxide dismutase mimetic activity (Naithani et al., 2006), among others. In addition, Folin-Ciocalteu's phenol reagent, reducing ability, radical scavenging potential using 2 , 2-diphenyl-1-picrylhydrazyl (DPPH), and 2,2'-azino-bis(3-ethylbenzothiazoline-6-sulfonic acid (ABTS) have been widely employed to determine antioxidant potential of bioactive compounds (Shahidi and Zhong, 2015). In addition, cell-based assays have also been developed to evaluate antioxidant potential through cellular antioxidant activity (CAA), which was first reported by Wang and Joseph (1999), and is now widely used to measure antioxidant activity and bioavailability of bioactives from natural products by considering cellular uptake and metabolism.

Recently, the above colorimetric assays have been criticized by some researchers due to the lack of standardized procedures and 
the weak correlation between antioxidant screening assays and biological evaluation methods. However, given that individual assays have pros and cons due to the discrepancies in the reaction medium and applied biological systems, the use of various assays to address the drawbacks of each would be necessary to acquire realistic and trustworthy data from experimental trials.

In this contribution, detailed principles and practical uses of various methodologies including colorimetric antioxidant screening assays, cell lines, and animal tests as well as lipid oxidation measurement assays are thoroughly discussed.

\section{Methodologies for the extraction of bioactives from natural sources}

\subsection{Pulsed-electric field extraction (PEF)}

Pulsed electric field (PEF), a non-thermal treatment, uses short pulses of electricity to improve the extraction of bioactive compounds in foods. The basic principle for improvement in the extraction yield using PEF is to accelerate the disintegration of the cell membranes in food by using an electric field that passes through them (Azmir et al., 2013). Briefly, at a critical value of transmembrane potential (>1 $\mathrm{V})$, repulsion between charge carrying molecules occurs due to the dipole nature of membrane molecules, which leads to the formation of pores and increases the permeability of solvent into the intracellular space of plant and animal cells (Bryant and Wolfe, 1987). The efficiency of PEF depends on many parameters such as field strength, energy input, pulse number, temperature and physical and chemical properties of the samples (Heinz et al., 2003).

PEF has been extensively used to enhance the efficiency of extraction yield of foods. Guderjan et al. (2005) reported that the application of PEF increased the extraction yield of phytosterol from maize and genistein and daidzein from soybeans by up to 32.4 and $21.0 \%$, respectively. The PEF treatment also increased the extraction rate of phenolics such as anthocyanins. For example, Corralesa et al. (2008) found that PEF treatment provided useful means to extract anthocyanin monoglucosides in grape by-products. This treatment also improved the extraction of polyphenols and anthocyanins in Merlot skin (Delsart et al., 2012). Liu et al. (2018) studied the effect of PEF treatment on the extraction yield of water-soluble phenolics in onion and found that PEF significantly elevated the extraction yield of phenolics and this was well reflected in their antioxidant potential. Moreover, PEF treatment increased the extraction yield of polyphenols in tea leaves by two times compared to the conventional thermal methods without any significant changes in phenolic composition as evidenced by mass spectrometry analysis (Liu et al., 2019). Bozinou et al. (2019) reported that the highest extraction yield in PEF treatment was found at a field strength of $7 \mathrm{kV} / \mathrm{cm}$ for $40 \mathrm{~min}$ in the extraction of phenolics from freeze-dried leaves of Moringa oleifera.

\subsection{Pressurized liquid extraction (PLE)}

Pressurized liquid extraction (PLE), which utilizes high pressure and temperature, is an advanced technique to isolate analytes from natural products by the residual or remaining solvent beyond their normal boiling point (Klejdusa et al. 2009). Pressurized liquid extraction was first described by Richter et al. (1996), but since then this method has also been referred to as high pressure solvent extraction (HSPE), pressurized fluid extraction (PFE), enhanced solvent extraction (ESE), and accelerated fluid extraction (ASE)
(Nieto et al., 2010). PLE treatment is carried out in a stainless steel extraction cell where the solid sample is placed in which a wide range of pressure $(500-3,000 \mathrm{psi})$ and temperature $\left(40-200{ }^{\circ} \mathrm{C}\right)$ are applied to optimize the extraction rate of desired compounds in samples, leading to the decreased extraction time and the amount of solvent required (Garcia-Salas et al., 2010). The proper combination of high pressure and temperatures enables the use of a lesser amount of solvent for the extraction of bioactive molecules. The remaining solvent beyond their normal boiling point at the optimized temperature and pressure not only increases the solubility of analyte and its mass transfer rate, but also decreases the viscosity and the surface tension of solvents (Ibañez et al., 2012).

PLE has been widely used to extract bioactive compounds in food matrices to improve their extraction efficiency. Erdogan et al. (2011) optimized the extraction condition of PLE to obtain bioactive compounds such as gallocatechin, catechin, epicatechin gallate, caffeic acid, chlorogenic acid, and myricetin from Anatolia propolis. Setyaningsih et al. (2016) attempted a number of combinations including solvent composition, extraction temperature, pressure, and static extraction time, among others, to find optimum combination for the extraction of bioactive compound in rice (Oryza sativa) grains, and they found that the extraction temperature, solvent and static extraction time were the most important factors in the extraction of bioactives using PLE treatment. The application of PLE was also extended to the extraction of isoflavones. Rostagno et al. (2004) optimized the extraction condition of PLE to isolate isoflavones in soybean. The best condition of PLE was $0.1 \mathrm{~g}$ of sample, $100{ }^{\circ} \mathrm{C}$, and three $(7 \mathrm{~min})$ static extraction cycles. They also reported that malonyl glucoside was degraded at temperatures higher than $100{ }^{\circ} \mathrm{C}$. Luthria (2008) emphasized that temperature, pressure, solid-to-solvent ratio, and particle size were the significant parameters in the use of PLE for the extraction of phenolics from parsley (Petroselinum crispum) flakes.

\subsection{Microwave assisted extraction (MAE)}

Microwave is a wavelength range from $1 \mathrm{~mm}$ to $1 \mathrm{~m}$ along with frequencies from $300 \mathrm{MHz}$ to $300 \mathrm{GHz}$. This long-wavelength consists of two oscillating fields such as electric field and magnetic field, which are perpendicular (Azmir et al., 2013). The generation of heat by microwave is caused by the strong rotation of the dipole molecule upon the absorption of microwave (Jain, 2009). In addition, heat is also generated by the collision of molecules due to the frequent changes in the direction of the field sign. Alupului (2012) described three main steps regarding the MAE applied extraction of bioactive molecules from food matrices; the isolation of bioactives from the active sites of food matrices at high pressure and temperature, the diffusion of solvents to the sample matrices, and the liberation of bioactive compounds to the solvents. This mechanism facilitates the extraction of desired compounds from samples and increases the extraction efficiency.

The MAE is a well proven efficient method for the extraction of bioactive compounds from foods. Lovrić et al. (2017) tested the effectiveness of microwave-assisted extraction in the isolation of phenolics in blackthorn flowers in which they used three different microwave powers of 100, 200 and $300 \mathrm{~W}$. High microwave power showed stronger effectiveness in the extraction yield of phenolics, and this was well reflected in their antioxidant potential using the 2,2-diphenyl-1-picrylhydrazyl radical scavenging capacity assay. However, long extraction time $(>5 \mathrm{~min})$ in microwave treatment caused the degradation of phenolics, which led to a decrease in their antioxidant capacity. Pan et al. (2003) tested the efficiency of MAE treatment in the extraction of phenolics from green tea leaves 
by comparison with the conventional extraction methods (without microwave treatment). This strongly supports the effectiveness of MAE treatment in the extraction of bioactive compounds. A higher extraction rate was also found in the isolation of flavolignin and silybinin from Silybum marianum by MAE treatment (Dhobi et al., 2009). In another study, the usefulness of MAE was confirmed in the liberation of insoluble-bound phenolic acids from bran and flour fractions of sorghum and maize (Chiremba et al. 2012).

\subsection{Supercritical fluid extraction (SFE)}

The use of supercritical fluid was first reported by Zosel (1964) who applied it for the decaffeination of coffee. Subsequently, SFE has been widely used in other fields such as environmental, pharmaceutical and polymer applications and food analysis (Zougagh et al., 2004). A substance reaches the supercritical state once it is present at the temperature and pressure beyond its critical point (Inczedy et al., 1998). Supercritical fluid has gas-like properties in diffusion, viscosity, and surface tension, and liquid-like density, which leads to the reduced extraction time and increased extraction yield (Sihvonen et al., 1999).

Supercritical carbon dioxide $\left(\mathrm{SC}-\mathrm{CO}_{2}\right)$ is the most common solvent in the utilization of SFE due to its critical conditions such as temperature $\left(31.1^{\circ} \mathrm{C}\right)$ and pressure $(73.8 \mathrm{MPa})$ (Garcia-Salas et al., 2010). However, it has a limitation in the extraction of polar compounds such as phenolics by the non-polar nature of $\mathrm{SC}-\mathrm{CO}_{2}$. In order to address this drawback, chemical modifiers have been widely used. For example, a small amount of dichloromethane $\left(\mathrm{CH}_{2} \mathrm{Cl}_{2}\right)$ significantly enhanced the polarity of carbon dioxide (Hawthorne et al., 1994).

Supercritical fluid extraction has been extensively used to extract bioactive compounds in natural products. SFE method was employed to extract naringin from citrus paradise, and the use of ethanol $(15 \mathrm{wt} . \%)$ as a modifier or co-solvent significantly increased the extraction yield of naringin at $9.5 \mathrm{MPa}$ and $58.6^{\circ} \mathrm{C}$ (Giannuzzo et al., 2003). Khorassani and Taylor (2004) employed SFE method to extract catechin and procyanidins from grape seed. The inclusion of methanol as a modifier elevated the extraction yield of catechin and procyanidins by more than $79 \%$. Alkaloids such as theobromine and theophylline were extracted from Ilex paraguaryensis (herbal mate tea) using SFE along with a wide range of temperature $\left(13-343{ }^{\circ} \mathrm{C}\right)$ and pressure (14-24 MPa) (Saldaña et al., 1999). Verma et al. (2008) utilized SFE to extract indole alkaloids such as catharanthine from Catharanthus roseus leaves and reported that the optimum condition for the extraction of catharanthine was at $25 \mathrm{MPa}$ and $80{ }^{\circ} \mathrm{C}$ using $6.6 \%$ methanol as a modifier. Thus, supercritical fluid extraction has been well proven as an excellent means for the extraction of bioactive compounds from natural products.

\subsection{Ultrasound-assisted extraction (UAE)}

Ultrasound is a special type of sound wave with frequencies beyond the upper audible limit of human hearing, which passes through a medium by generating compression and expansion. The ultrasound energy facilitates the release of bioactive compounds by assisting the access of solvent to the food matrices in which ultrasound energy enhances the diffusion of solvent across the cell wall and rinsing the cell components upon the disintegration of cells (Herrera and Luque de Castro, 2005).

UAE has been widely used to improve the extraction efficiency of bioactive compounds in food matrices. Vilkhu et al (2008) reported that UAE improved the extraction yield of bioactives from plant- and animal-based foods by 6 to $35 \%$. The advantages of UAE include reducing extraction time, energy, and use of solvent. Moreover, this approach increases the stability of bioactive compounds during extraction compared to other extraction methods that use high temperature and pressure (Chemat et al., 2017). UAE was also applied to isolate alkaloids and phenolic acids from natural products. Yang et al. (2011) employed ionic liquid-based UAE to extract three alkaloids, namely vindoline, catharanthine and vinblastine from Catharanthus roseus. Zu et al. (2012) also utilized ionic liquid-based UAE to extract phenolcarboxylic acids, carnosic acid and rosmarinic acid from Rosmarinus officinalis.

\section{In vitro assays for measuring antioxidant capacity}

\subsection{Semi-quantification of phenolics by total phenolic content (TPC) assay}

TPC is the most common and practical assay to determine the level of phenolics in natural sources using Folin-Ciocalteu reagent containing phosphomolybdic/ phosphotungstic acid complexes. The basic principle of the TPC assay is based on the electron-transfer reaction of antioxidants to form phosphomolybdic/phosphotungstic acid complexes in an alkaline medium. This reaction produces a blue-colored chromophore that is detectable at $700 \mathrm{~nm}$ with a $\mathrm{UV} / \mathrm{visible}$-spectrophotometer. The exact mechanism for the formation of the complex so formed has not yet been established, however it is assumed that the reaction might involve a reversible one- or two-electron reduction reaction (Huang et al., 2005; Singleton et al., 1999; Ainsworth and Gillespie, 2007).

Despite the excellent performance of TPC assay in measuring the tentative quantification of phenolics in natural sources, there are criticisms for the utilization of TPC assay due to the poor selectivity of Folin-Ciocalteu reagent in the reaction medium; namely, this reagent can also react with some amino acids in addition to phenolic compounds. In this sense, Harnly (2017) argued that "Only state-of-the-art techniques such as liquid chromatography-mass spectroscopy (LC-MS) to identify and quantify phenolics should be used in scientific research". Without a doubt, the advanced high techniques such as HPLC and HPLC-MS or (MS/MS) have an excellent performance in the identification and quantification of molecules in samples along with extremely high accuracy and sensitivity. However, HPLC system scans relatively a narrow range of compounds, compared to TPC, due to the specified analysis conditions such as wavelength, packing material of column, and composition of mobile phase, among others, which is optimized to detect targeted compounds. This indicates that some compounds may not be detected in HPLC analysis under certain analysis condition. Here, TPC assay may provide a useful means to complement the aforementioned flaw of HPLC analysis by detecting all molecules that react with Folin-Ciocalteu reagent. Thus, it is important to reconcile two different assays to address the disadvantages of each method.

\subsection{2,2-Diphenyl-1-picrylhydrazyl (DPPH) radical scavenging assay and Trolox equivalent antioxidant capacity (TEAC) assay}

The practical use of 2,2-diphenyl-1-picrylhydrazyl (DPPH) radical to measure the antioxidant potential of bioactive compounds was proposed more than 50 years ago (Blois, 1958; Papariello and Janish, 1966). The outstanding stability of this free radical, compared to other free radicals such as hydroxyl $(\mathrm{HO} \bullet)$, lipid alkyl 
$(\mathrm{L} \bullet)$, alkoxyl $(\mathrm{LO} \bullet)$, lipid peroxyl (LOO•) radicals, allows its common use in assessing hydrogen atom or electron donating potential of antioxidants. The reaction mechanism of this assay is based on the neutralization of DPPH radical by receiving a hydrogen atom or an electron from antioxidants followed by a color change from purple to yellow. The alteration is detectable by ultraviolet-visible spectrophotometry at $\lambda_{\text {max }} 517 \mathrm{~nm}$. The broad utilization of DPPH assay in the related fields such as food, medicine, and cosmetic, demonstrating its excellent performance in testing radical scavenging potential of bioactive molecules (Halliwell, 1997; Liu, 2003; Sánchez-Moreno, 2002). Moreover, the long history of DPPH assay has developed DPPH chemistry such as stoichiometry factor (n), defined as "number of electron or hydrogen atoms that antioxidants can donate to the free radicals", and their mechanisms under versatile reaction environments such as temperature, $\mathrm{pH}$, and polarity of the solvent (Yeo and Shahidi, 2019a; Yeo and Shahidi, 2019b; McGowan et al., 1959; Dawidowicz et al., 2012).

Miller et al. (1993) introduced TEAC assay to assess the electron donating potential of antioxidants using 2,2'-azinobis (3-ethylbenzothiazoline-6-sulfonic acid $\left(\mathrm{ABTS}^{+}\right)$. The chemical reaction between $\mathrm{ABTS}$ and the strong oxidizing agent potassium persulfate produces the blue/green ABTS $\bullet^{+}$chromophore, having maximum absorption at 645,734 , and $815 \mathrm{~nm}$ (Miller et al., 1993). The addition of antioxidants to the solution of ABTS $\bullet^{+}$chromophore neutralizes ABTS $\bullet^{+}$ via electron or hydrogen atom donation, which displays the decolorization of the radical cation, leading to the absorption decrease at 645, 734, and $815 \mathrm{~nm}$ (Shahidi and Zhong, 2015). ABTS • ${ }^{+}$is applicable in a wide range of solvent system due to its high solubility in both hydrophilic and lipophilic media (Arnao, 2000).

Despite the great performance of DPPH radical scavenging capacity and TEAC assays, it has been a debate as to whether these two assays are appropriate means to measure electron or hydrogen atom donating ability of antioxidants due to the discrimination with reactive oxygen species (ROS) which are found in real food and biological systems (Benzie and Strain, 1999). This criticism has led to the application of more relevant radicals such as hydroxyl radical to evaluate the scavenging potential of test materials and to complement the drawback of DPPH and TEAC assays.

\subsection{Hydroxyl radical scavenging potential}

Hydroxyl radical is produced from $\mathrm{O}_{2}{ }^{-}$and $\mathrm{H}_{2} \mathrm{O}_{2}$ in the presence of transitional metal ions during Fenton reaction. The excessive production of hydroxyl radicals causes oxidative stress, leading to the damage of cells. For instance, Rojanasakul et al. (1993) reported that hydroxyl radicals cause a cytotoxic effect in alveolar macrophages via the elevation of $\left[\mathrm{Ca}^{2+}\right]$ concentration, which further interferes with homeostasis and cell death. Moreover, hydroxyl radical is responsible for the endogenous oxidation of cellular DNA (Cadet et al., 1999). Thus, the prevention of the excessive level of hydroxyl radical in cellular space is crucial, and antioxidants (free radical scavengers) have been well proven for controlling the level of hydroxyl radicals. Alshikh et al. (2015) measured hydroxyl radical scavenging ability of five lentil cultivars, namely CDC SB-2, 3494-6, CDC invincible, CDC green land, and Maxim using electron paramagnetic resonance (EPR). Among the three free, esterified, and insoluble-bound fractions, the esterified fraction showed a better hydroxyl radical scavenging ability than the others, and they concluded that the result might be related to the high content of flavonoids in the esterified fraction. In addition, hydroxyl radical scavenging ability had a high correlation coefficient with total phenolic content (TPC) and total flavonoid content (TFC), as well as the condensed tannin content (CTC). Hydroxyl radical scavenging ability was also employed to determine the antioxidant potential of lentil hulls (Yeo and Shahidi, 2020).

\subsection{Inhibitory activity against the oxidation of LDL cholesterol}

LDL cholesterol transports lipophilic compounds such as fatty acids, triacylglycerols, cholesterol, and cholesterol esters to the cell intracellular space, playing a crucial role in the growth and maintenance of cells. Nevertheless, they are referred to as "bad cholesterol", since they are responsible for causing cardiovascular disease; briefly, once they are oxidized, they accumulate at the arterial wall, leading to a narrowing of blood vessels. Thus, the inhibitory activity against the oxidation of LDL cholesterol is important for preventing possible vascular diseases.

The determination of inhibitory activity against the oxidation of LDL cholesterol starts with the dialysis treatment to remove ethylenediaminetetraacetic acid (EDTA) which is added to prevent possible oxidation of LDL cholesterol during storage. The purified LDL cholesterol is subjected to the oxidation process in the presence of a transitional metal ion such as copper ion $\left(\mathrm{Cu}^{2+}\right)$ to induce lipid oxidation. Peroxyl radical is also used to induce the oxidation of LDL cholesterol by the inclusion of 2,2'-azobis (2-methylpropionamidine) dihydrochloride (AAPH). The mixture of LDL cholesterol and prooxidant is incubated at the physiological temperature of $37^{\circ} \mathrm{C}$, and the degree of LDL cholesterol oxidation is measured by monitoring the formation of conjugated dienes of phospholipids or triacylglycerols of LDL cholesterol at $234 \mathrm{~nm}$ using UV-visible spectrophotometry. The inhibitory activity against the oxidation of LDL cholesterol has been widely employed by many researchers to evaluate antioxidant capacity and potential anti-atherogenic effect of extracts of natural products (Chandrasekara and Shahidi, 2011; Madhujith and Shahidi, 2007; Zhong and Shahidi, 2012).

\subsection{Inhibitory activity against DNA oxidation}

The oxidation and damage to DNA strand result in the mutation of cells, which leads to their dysfunction. Thus, suppression of DNA oxidation is vital to maintain the health of cells. In this assay, the oxidation of DNA strand is induced by hydroxyl or peroxyl radicals to determine the inhibitory activity of antioxidants against the oxidation of a supercoiled plasmid pBR322 DNA (Chandrasekara and Shahidi, 2011; Zhong and Shahidi, 2012). The scission of DNA strand due to oxidation is determined by gel electrophoresis, and bands are analyzed after visualization. The level of intact supercoiled DNA strand and nicked DNA fractions is measured by densitometry as indicated by the intensity. The inhibitory activities of phenolics in barley (Hordeum vulgarae L.) and different oat (Avena sativa) cultivars against the oxidation of DNA strand were determined, and they confirmed the high effectiveness of phenolics in preventing the scission of supercoiled DNA strand by hydroxyl radical (Madhujith and Shahidi, 2007; Singh et al., 2019). Alshikh et al. (2015) measured the inhibitory activity of phenolics in lentil cultivars in the formation of nicked or linear form of DNA strand upon oxidation. The inhibition of the DNA strand scission of phenolics in six lentil cultivars ranged from 28.1 to $91.7 \%$.

\section{Measuring the absorption rate of antioxidants in in vivo system}

The absorption of antioxidants takes place mainly at the lumen of 


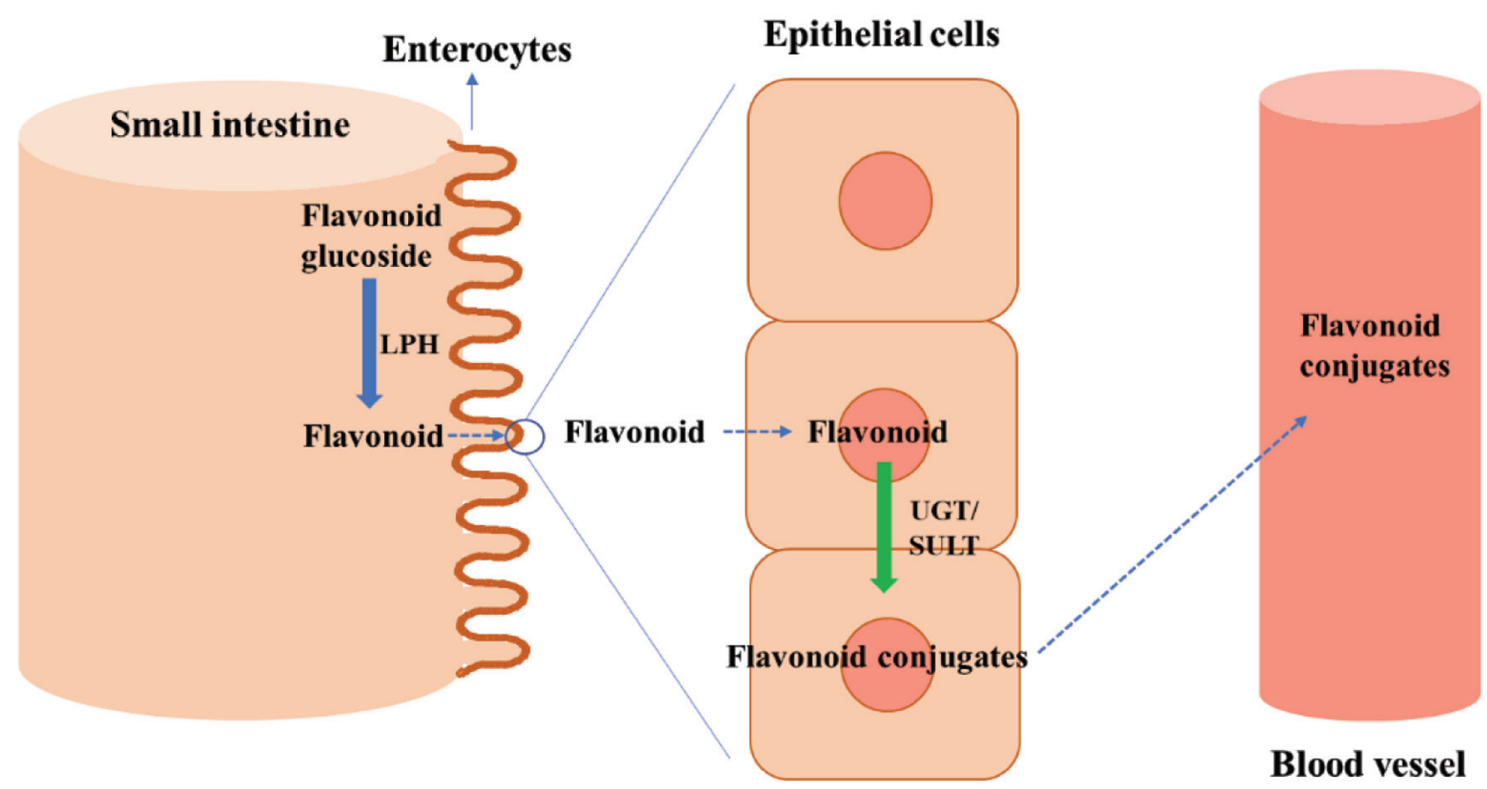

\section{LPH, lactase phlorizin hydrolase; UGT, uridine diphosphate glucuronosyl transferase; SULT, sulfotransferase}

Figure 1. Absorption mechanism of flavonoid glucosides in the small intestine.

small intestine, followed by their circulation in bloodstream and further phase II metabolism in liver. In this contribution, flavonoid glucoside was selected as an example to explain the absorption mechanism of antioxidants in the small intestine. The detailed mechanism of the absorption of flavonoid glucoside in the small intestine and into the bloodstream is described in Figure 1. Briefly, flavonoid glucosides that are introduced in the small intestine after the ingestion of food undergo deglucosylation by lactase phlorizin hydrolase (LPH) in the brush-border of small intestine. This process increases the lipophilicity of flavonoids by removing the hydrophilic sugar moiety of the glucoside form, facilitating the passive diffusion of them in the membrane of the epithelial cells. The flavonoid aglycone in the epithelial cells undergoes sulfation, glucuronidation, and methylation by the enzymes such as sulfotransferase, uridine diphosphate glucuronosyl transferase (UGT), and catechol- $O$-methyltransferases, leading to the formation of flavonoid conjugates. These processes again enhance the hydrophilicity of the flavonoids, followed by the improvement of their solubility in the plasma. Once introduced into the bloodstream, they are subjected to phase II metabolism in the liver before urinary excretion.

Many studies have so far been conducted on the absorption of antioxidants in rat and human trials (Table 1). Chesson et al. (1999) investigated the absorption rate of hydroxycinnamates in a rat model system and found that $25 \%$ of consumed ${ }^{14} \mathrm{C}$-labeled hydroxycinnamates were observed in body tissue after 2 hours. Adam et al. (2002) determined the absorption rate of ferulic acid in rat system by feeding ferulic acid-enriched semi-purified diets. The result showed that approximately $50 \%$ of ingested ferulic acid was found in the urine; they suggested the absorption of the compounds through the passive diffusion or $\mathrm{Na}^{+} /$dependent carrier-mediated transport process in the small intestine. A large proportion of ferulic acid was found in the conjugated form such as sulfated metabolites $(58 \%)$ and glucuronidated metabolites $(18 \%)$ in plasma, which may occur in the small intestine, liver, and kidney by the enzymatic reaction of sulfatase or $\beta$-glucuronidase (Karakaya, 2004). Wolffram et al. (1995) studied the mechanism of human test by observing the level of their metabolites in plasma after the ingestion of lightly fried onions. Five metabolites such as quercetin-3-O-glucuronide, quercetin-3-sulfate, isorhamnetin3-O-glucuronide, quercetin- $O$-glucuronide-sulphate, and quercetin- $O$-diglucuronide were found in plasma, and they concluded that the absorption of quercetin and isorhamnetin derivatives may occur in the proximal part of the small intestine. Ottaviani et al. (2012) reported that (-)-epicatechin, (+)-catechin, and (-)-catechin ingested as the cocoa-based drink were metabolized into (-)-epicatchin-3'-O-glucuronide and (-)-epicatchin-3'-sulfate in plasm in human body. Actis-Goreta et al. (2012) also observed the absorption of (-)-epicatechin, (+)-catechin, and (-)-catechin after the ingestion of dark chocolate containing (-)-epicatechin, $(+)$-catechin, and $(-)$-catechin in human system. They identified same metabolites such as (-)-epicatchin- $3^{\prime}-O$-glucuronide and (-)-epicatchin-3'-sulfate in plasma as well as their additional work showed the approximately $20 \%$ of urinary recovery of tested compounds (Ottaviani et al., 2012). Prior (2012) studied the absorption of anthocyanins in raspberries such as cyanidin-3-O-sophoroside, cyanidin-3-O-(2'-O-glucosyl) rutinoside, cyanidin-3-O-glucoside, and cyanidin-3-O-rutinoside and found only two corresponding metabolites such as cyanidin-3-O-glucoside and cyanidin- $O$-glucuronide in plasma along with only $0.007 \%$ of urinary recovery. In short, most of the antioxidants were absorbed in the small intestine, and subsequently changed their structures via enzymatic reaction at the sulfatase and $\beta$-glucuronidase in the small intestine, liver, and kidney. This process increases the polarity of antioxidant metabolites, thus facilitating their solubility in blood and then circulation in whole body.

\section{Application of cell lines for measuring antioxidant potential}

The chemical methods such as radical scavenging ability, reducing power, and TPC provide important preliminary information 
Table 1. Methods for measuring the absorption of antioxidants and their metabolites in rat and human systems

\begin{tabular}{|c|c|c|c|c|}
\hline Antioxidant & Method & Result & Mechanism & Reference \\
\hline $\begin{array}{l}\text { Hydroxycinnamic } \\
\text { acid }\end{array}$ & $\begin{array}{l}\text { Feeding }{ }^{14} \mathrm{C} \text {-labeled } \\
\text { hydroxycinnamates (Rat) }\end{array}$ & $\begin{array}{l}\text { Observation of } 25 \% \text { of } \\
\text { labeled hydroxycinnamates } \\
\text { in body tissue after } 2 \mathrm{~h}\end{array}$ & - & Chesson et al. (1999) \\
\hline Ferulic acid & $\begin{array}{l}\text { Feeding FA-enriched } \\
\text { sem-purified diets (Rat) }\end{array}$ & $\begin{array}{l}\text { Recovery of }<50 \% \text { the } \\
\text { ingested dose in urine }\end{array}$ & $\begin{array}{l}\text { Passive diffusion } \\
\text { or } \mathrm{Na}+/ \text { dependent } \\
\text { carrier-mediated } \\
\text { transport }\end{array}$ & Adam et al. (2002) \\
\hline Cinnamic acid & $\begin{array}{l}\text { Mucosal uptake } \\
\text { technique (in vitro) }\end{array}$ & - & $\begin{array}{l}\mathrm{Na}+/ \text { dependent } \\
\text { carrier-mediated } \\
\text { transport }\end{array}$ & Wolffram et al. (1995) \\
\hline $\begin{array}{l}\text { Quercetin and } \\
\text { isorhamnetin } \\
\text { glucosides }\end{array}$ & $\begin{array}{l}\text { Ingestion of } 270 \mathrm{~g} \text { of } \\
\text { fried onions containing } \\
\text { quercetin and isorhamnetin } \\
\text { glucosides (Human) }\end{array}$ & $\begin{array}{l}\text { Detection of five metabolites } \\
\text { after sulfation and } \\
\text { glucuronidation in plasma }\end{array}$ & $\begin{array}{l}\text { Proximal part of } \\
\text { the small intestine }\end{array}$ & Mullen et al. (2006) \\
\hline $\begin{array}{l}\text { (-)-Epicatechin, } \\
(+) \text {-catechin, and } \\
(-) \text {-catechin }\end{array}$ & $\begin{array}{l}\text { Ingestion cocoa-based drink } \\
\text { containing epicatechin } \\
\text { and catechin (Human) }\end{array}$ & $\begin{array}{l}\text { Detection of trace amounts of } \\
\text { metabolites such as (-)-epicatchin- } \\
3^{\prime} \text {-O-glucuronide and (-)-epicatchin- } \\
3^{\prime} \text {-sulfate in plasma }\end{array}$ & $\begin{array}{l}\text { Absorption in } \\
\text { the small intestine }\end{array}$ & Ottaviani et al. (2012) \\
\hline $\begin{array}{l}\text { (-)-Epicatechin, } \\
\text { (+)-catechin, and } \\
(-) \text {-catechin }\end{array}$ & $\begin{array}{l}\text { Ingestion of dark } \\
\text { chocolate and measuring } \\
\text { metabolites in plasma } \\
\text { and urine (Human) }\end{array}$ & $\begin{array}{l}\text { Detection of metabolites such as } \\
\text { (-)-epicatchin-3'-O-glucuronide and } \\
\text { (-)-epicatchin-3'-sulfate in plasma and } \\
\text { approximately } 20 \% \text { of urinary recovery }\end{array}$ & - & $\begin{array}{l}\text { Actis-Goreta et } \\
\text { al. (2012) }\end{array}$ \\
\hline Anthocyanins & $\begin{array}{l}\text { Ingestion of raspberries } \\
\text { containing cyanidin-based } \\
\text { anthocyanins (Human) }\end{array}$ & $\begin{array}{l}\text { Detection of two metabolites such } \\
\text { as cyanidin-3-O-glucoside and a } \\
\text { cyanidin- } O \text {-glucuronide in plasma } \\
\text { and } 0.007 \% \text { of urinary recovery }\end{array}$ & - & Prior, (2012) \\
\hline
\end{tabular}

in the determination of the antioxidant potential of test materials. However, given the complex pathways for the suppression of oxidative stress in biological systems including up-regulation of antioxidant enzymes, modulation of gene expression, and changing cell signalling, the use of chemical assays is insufficient to predict the effectiveness of antioxidants in biological systems (Jones, 2006). The occasional lack of correspondence between the biological system and the aforementioned chemical assays has led to the development of cellular antioxidant assays (CAA) (Wang and Joseph (1999). The central principle of the CAA is based on the combination of chemical assays and cellular system to predict the inhibition capacity of antioxidants against reactive oxygen species (ROS) generated in cultured cell lines. Briefly, the $2^{\prime}, 7^{\prime}$-dichlorofluorescin diacetate (DCFH-DA) introduced to the cellular system is deacylated by the cellular esterases, then the DCFH is oxidized by ROS and reactive nitrogen species (RNS) such as nitric oxide and peroxynitrite, followed by alteration into DCF (Wolfe et al., 2008; Wolfe and Liu, 2007). The intensity of DCF is recorded using a fluorescence spectrometer by exploiting its fluorescent property $(\lambda \operatorname{exc}=485 \mathrm{~nm}, \lambda \mathrm{em}=535 \mathrm{~nm})$.

Many experts have employed CAA to assess the antioxidative potential of bioactive compounds from natural sources such as fruits, vegetables, and legumes (Song et al., 2010; Wolfe et al., 2008; Wolfe and Liu, 2007). Blasa et al. (2011) measured the cellular antioxidant activity of botanical extracts using red blood cells (CAA-RBC). Aside from those aforementioned reports, cellular antioxidant activity assay was also conducted in the different cell lines such as human gastric adenocarcinoma cell line, vascular endothelial cells EA.hy926, human macrophage cell line U937, and human lung fibroblasts(WI38, IMR-90) (Sessa et al., 2011; Xu and
Chang, 2010; Ziberna et al., 2010; Roy et al., 2009). However, CAA revealed a limitation by displaying a substantial variation in the different cell lines. Myricetin showed a similar CAA with kaempferol in red blood cells (RBD) by displaying 82.2 and 80.4 $\mu \mathrm{mol}$ of QE/100 $\mu \mathrm{mol}$, whereas in HepG2 cells, more than seven times lower CAA of myricetin was found compared to kaempferol (Wolfe et al., 2008; Blasa et al., 2011). Moreover, a high CAA of catechin in Caco-2 cells showed contrary results in HepG2 and red blood cells by showing only a minor effect. In addition, Kellett et al. (2018) compared CAA of catechin and quercetin in different cell lines; namely, catechin did not show cellular antioxidant activity in HepG2 cells, whereas it suppressed $54.1 \%$ of oxidation in Caco- 2 cells. Moreover, quercetin had a ten times higher inhibition in Caco-2 cells compared to HepG2 cells. They assumed that the discrepancy might be due to the difference of the active membrane transport of those flavonoids in the two cell lines.

\section{Measuring antioxidant potential in animal models}

\subsection{Zebrafish model}

Zebrafish has been widely used as a vertebrate model organism in scientific research such as ecotoxicology and developmental biology. Due to its convenience in use and cost-effectiveness, the application of zebrafish model has been largely extended to other fields such as medicine, neurosciences and cancer research and food science as well as testing of cosmetics where the use of other animal models is not considered acceptable to some consumers 
(Kinth et al., 2013). Zebrafish has similar physiology and anatomy to mammals as well as being present orthologous genes for $70 \%$ of the human ones. However, the central reasons for the wide use of Zebrafish in research area are the low cost for maintenance and experimentation, their high fecund and rapid breeding, and the feasibility of the in vivo visualization of complex responses (Caro et al., 2016).

The antioxidants activity of bioactives in zebrafish model can be determined through the direct measurement of reactive oxygen species production and biomarkers produced by oxidative damage under both normal physiological conditions and after treatment with an oxidative stressor (Caro et al., 2016). Among those approaches in zebrafish model, the primary method to investigate the antioxidant activity of bioactives is to detect the quantity of ROS using fluorescence indicators. For that, fluorescent probes such as DCFH-DA (dichlorodihydrofluorescein diacetate) and HPF (hydroxyphenyl fluorescein) are utilized in which these fluorescent probes emit a fluorescence signal once they are oxidized by ROS. Thus, this method enables rapid and direct detection of oxidative stress (Caro et al., 2016). For instance, Yang et al. (2012) used DCFH-DA to detect the generation of ROS in zebrafish upon ultraviolet (UV) B radiation and to investigate the antioxidant effect of quercitrin. Moreover, other studies have utilized zebrafish model to explore the bioactivity of antioxidants. For example, Shih et al. (2012) demonstrated the potent antioxidant effect of 3',4'-diaminoflavones using zebrafish larvae and Chen et al. (2012) also used this model to evaluate the antioxidant effect of several flavonoids. Furthermore, the antioxidant activity of bioactives was determined by monitoring oxidative stress-induced cell death in a zebrafish model. Yang et al. (2012) and Shih et al. (2012) counted stressinduced cell death in zebrafish model to evaluate the antioxidant potential of quercitrin and 3',4'-diaminoflavones.

Lipid peroxidation markers such as malondialdehyde (MDA) are also used to measure the antioxidant potential of bioactives in zebrafish model. Kim et al (2012) reported the potent antioxidant activity of acai puree by showing the suppressed the hepatic MDA level in hypercholesterolemic zebrafish after feeding acai puree. Moreover, MDA was the efficient lipid peroxidation biomarkers in zebrafish model in examining their vitamin C deficiency; zebrafish suffering vitamin $\mathrm{C}$ deficiency showed a high MDA level, which subsequently affected their energy metabolism (Kirkwood et al., 2012).

\subsection{Caenorhabditis elegans model}

Caenorhabditis elegans has been employed as a model system to investigate the bioactivities of antioxidants such as anti-inflammatory, antioxidant, chemopreventive, and chemotherapeutic activities as well as inhibiting obesity, aging, and Alzheimer's disease since the early 1960s (Shen et al., 2017). This organism has many advantages as a model system in lab research such as convenience to cultivate in laboratory, short life-cycle ( 3.5 days from the eggs to adult worms) and high reproducibility (they produce over 1,000 eggs every day), and easy to observe using a microscope due to the transparency of their body (Luo et al., 2019). Thus, Caenorhabditis elegans has been widely used to measure the bioactivities of antioxidants (Shen et al., 2017). Liao et al. (2011) explored the antioxidant potential of curcumin in Caenorhabditis elegans in which the extended lifespan of the organism was noticed. In this, curcumin suppressed the level of intracellular reactive oxygen species and lipofuscin in Caenorhabditis elegans during aging. Cañuelo et al. (2012) found that tyrosol markedly extended the lifespan of Caenorhabditis elegans as well as delaying the genera- tion of a biomarker relevant to ageing. In addition, other studies on the stress resistance of the extracts from natural products such as Sophora moorcroftiana and M. Willow bark in Caenorhabditis elegans model have also been reported (Zhang et al., 2018; Ishikado et al., 2013). The above examples strongly support the usefulness of Caenorhabditis elegans model to screen bioactivities of antioxidants.

\subsection{Fruit fly model}

Fruit fly (Drosophila melanogaster) has been used as a crucial model system for exploring the mechanisms regulating essential biological processes as well as understanding the molecular mechanisms of development and physiology (Arias, 2008). This further enabled a deep and comprehensive understanding of human diseases at the molecular level (Botas, 2007).

Fruit fly possesses analogous lipid metabolism and transport system to mammalian hepatocytes as well as having a short life span, which facilitates investigation of the inhibitory activity of bioactives against oxidative stress by measuring their lifespan (Gutierrez et al., 2007). Lin et al (2018) investigated the antiaging effect of sea cucumber (Cucumaria frondosa) hydrolysate in a fruit fly model and reported that these hydrolysates effectively extended the lifespan of fruit flies. Huangfu et al (2013) employed fruit fly model system to test the antiaging effects of astaxanthin-rich alga (Haematococcus pluvialis) in which it markedly enhanced their lifespan and reduced the age-related decline in locomotor function. Zou et al. (2017) studied the antiaging effect of riboflavin in fruit fly model system and found that riboflavin significantly extended the lifespan and reproduction of fruit fly by elevating superoxide dismutase 1 (SOD1) and catalase (CAT). Moreover, fruit fly was used to demonstrate the improvement of methionine sulfoxide reductase activity under the oxidative stress conditions by feeding methyl-cysteine fortified meals (Wassef et al., 2007).

\subsection{Mouce model}

Mouce model is the most common system to examine the antioxidant capacity of natural products. Prior to the testing antioxidant capacity, mice are treated with oxidative stressors such as 6-hydroxydopamine (6-OHDA), alloxan t-BHP, streptozotocin (STZ), high-fat diets, ethanol, and D-galactose (Zhang et al., 2017), then antioxidant capacity is determined by measuring the activity of antioxidant enzymes such as glutathione reductase and catalase and malondialdehyde (MDA) as the oxidative stress biomarkers (Zhang et al., 2017).

Recent literature in the use of mice model to measure the antioxidant capacity of natural products is summarized below. Lin et al. (2018) studied the effect of sea cucumber (Cucumaria frondosa) hydrolysate on the age-related neurodegenerative disorders in D-galactose-induced aging mice, and the results showed that sea cucumber hydrolysate significantly attenuated oxidative stress D-galactose-induced aging mice. Costa Barros-Gomes et al. (2018) measured the antioxidant potential of extract from Seaweed Gracilaria birdiae (GB) in mice model; GB extract decreased their weight gain and the level of blood sugar level after feeding 21 days of meals containing GB extract and enhanced the activity of antioxidant enzymes such as glutathione reductase and catalase. Aremu et al. (2019) examined antioxidant effect of 70\% ethanolwater (v/v) extract of Taraxacum officinale in $\mathrm{N \omega}$-nitro-L-arginine methyl ester (L-NAME)-induced hypertensive rats: The reduced MDA levels and increased total antioxidant capacities (TAC) 
were found in rats after feeding Taraxacum officinale extract for 21 days. Diabetic mice were also used to evaluate the antioxidant and anti-diabetic activity of polysaccharides from Guava (Psidium guajava L., Myrtaceae) leaves (Luo et al., 2019). Diabetic mice were induced by using streptozotocin combined with a high-fat diet; they were then fed with Guava leaves extract; the Guava leaves extract markedly improved TAC and superoxide dismutase (SOD) as well as suppressing the damage to liver, kidney, and pancreas. Tert-butyl hydroperoxide (t-BHP) has also been widely used to induce oxidative stress in mice models. Kim et al. (2015) utilized t-BHP to induce oxidative stress in mice to explore the antioxidant activity of extract from Celosia cristata L.flower. The Celosia cristata L. flower extract significantly reduced the hepatic levels of MDA and serum level of triacylglycerol against t-BHPinduced oxidative stress.

\section{Methods for measuring lipid oxidation for evaluating anti- oxidant effects}

\subsection{Lipid oxidation}

Autoxidation, the spontaneous chemical reaction of atmospheric oxygen with lipids, results in extensive alteration in chemical and physical properties of foods as well as biological systems (Shahidi and Zhong, 2010). Catalysts such as heat, light, enzymes, metals, metalloproteins and microorganisms are responsible for lipid oxidation, resulting in the formation of off-flavors and changes in the physical and chemical properties of foods. Reactive oxygen species (ROS) also cause lipid oxidation of cellular membrane in biological systems and this may lead to the destruction of cell life, followed by the increase in the incidence of chronic diseases such as inflammation, atherosclerosis and ageing, among others (Dalton et al.,1999; Davies, 2000; Kruidenier and Verspaget, 2012). Moreover, the formation of polymeric products by oxidation of phospholipids in cellular membranes deteriorates the membrane transport and cell signalling capacity as observed in Alzheimer's disease due to the reduced fluidity of the membrane (Lyras et al., 1997).

\subsection{Using HPLC for the determination of peroxide value (PV)}

Hydroperoxides $(\mathrm{ROOH})$ are the primary products of lipid oxidation and do not possess any off-flavour or off-odour by themselves. However, once they are broken down into smaller secondary products such as aldehydes, ketones, alcohols, esters, and hydrocarbons by $\beta$-scission, the resultant compounds generate off-flavour compounds with low threshold values (Shahidi and Zhong, 2010).

Peroxide value is a classical means for the quantitation of hydroperoxides produced from lipid oxidation using an iodometric method. The basic principle for measuring the level of peroxides in oxidized lipid relies on the reduction of the hydroperoxide group $(-\mathrm{OOH})$ by iodide ion under acidic condition. The amount of iodine $\left(\mathrm{I}_{2}\right)$ released in the above reaction is proportional to the level of peroxide in the reaction medium. The measurement of the liberated $\mathrm{I}_{2}$ is carried out by titration using sodium thiosulphate solution along with starch solution as indicator. Total amount of sodium thiosulphate solution required for the titration is used for the determination of the level of hydroperoxide in sample.

High performance liquid chromatography (HPLC) has been widely employed for the determination of the level of hydroperoxides in oxidized oil/fat. Wang and Joseph (1999) found a total of 11 hydroperoxide isomers in oxidized methyl linoleate using HPLC system. Browne and Armstrong, (2000) utilized reversedphase HPLC to assess lipid peroxidation in human blood plasma, and they identified 13 hydroxy- and hydroperoxy polyunsaturated fatty acids at $236 \mathrm{~nm}$ using UV-visible detector (UVD). Morales et al. (2014) investigated the formation of hydroperoxides from three sunflower oils with different levels of oleic and linoleic acids at the heating temperature of $40{ }^{\circ} \mathrm{C}$ using HPLC system equipped with two detectors such as UVD and evaporative light scattering detector (ELSD) in series. This method allowed the detection of oleate hydroperoxides and the simple hydroperoxydienes of linoleate and linolenate. In addition, Zeb, (2012) found epoxy hydroperoxides, epoxy epidioxides, and mono-epoxides as the oxidation products of camellia seed oil using liquid chromatography with electrospray ionization mass spectrometry (HPLC-ESI-MS).

\subsection{Conjugated dienes (CDs)}

Fatty acids containing methylene-interrupted dienes or polyenes such as linoleic, linolenic, and high polyunsaturated fatty acids can form conjugated double bonds through the shifting of electrons upon lipid oxidation. The resultant conjugated dienes or trienes are detectable at $\lambda_{\text {max }} 233-238 \mathrm{~nm}$ using UV-visible spectrophotometry. Conjugated dienes include lipid oxidation products having two or more double bonds in series such as trans, trans-2,4-alkadienals, trans, trans-2,6-nonadienal, and trans, trans-2,4-decadienal. Hydroperoxides also contain conjugated dienes in their chemical structure, except hydroperoxides formed from oleic acid having only one double bond.

The simple, low cost, procedure for measuring conjugated dienes enables the easy application of this procedure to a wide range of samples including food and biological materials. Yeo et al. (2011) evaluated the velocity of lipid oxidation of lard at four different temperatures using CDs, showing the increase of the rate of lipid oxidation depending on the intensity of heat energy. Interestingly, the level of CDs was reduced after the specific oxidation time at high temperatures such as 150 and $180^{\circ} \mathrm{C}$. They concluded that the decrease in CDs might be due to the degradation of hydroperoxides and CDs by high heat energy. Peña-Ramos and Xiong (2003) measured lipid oxidation of pork patties after cooking at 70 ${ }^{\circ} \mathrm{C}$ using $\mathrm{CDs}$; soy protein hydrolysate produced by chymotrypsin or Flavourzyme significantly inhibited the formation of CDs during cooking and storage at $4{ }^{\circ} \mathrm{C}$ for 7 days. Meanwhile, CDs assay has a serious limitation in the application of samples containing pigments such as carotenoids and phenolic compounds since these molecules interfere with the absorbance reading at 233-234 nm using UV spectrophotometry.

\subsection{Thiobarbituric acid (TBA) test}

The TBA test is an old and classic assay to assess the oxidation of fats and oils. Malondialdehyde (MDA) generated in lipid oxidation reacts with 2-thiobarbituric acid, forming the pink complex of TBA-MDA adduct being detectable at 530-532 nm. Aside from MDA, 2-alkenals and 2,4-alkedienals can also react with TBA, but the exact mechanism of the reaction is not yet well understood.

Zhou et al. (2019) measured the lipid oxidation of mussels (mytilus edulis) meat during storage at $4{ }^{\circ} \mathrm{C}$ for four days using TBA test. The increased TBA value was found with the storage time, and this showed high consistency with other measurements used such as volatile basic nitrogen (TVB-N), peroxide value (POV), and total oxidation (TOTOX). Liu et al. (2018) determined the lev- 
el of lipid oxidation of processed clam (Ruditapes philippinarum) by hot-air drying treatment using different assays such as TBA test, peroxide value (POV), total oxidation value (TOTOX), and oxidation test (OXITEST). In results, TBA test showed a similar trend with POV and TOTOX, whereas OXITEST displayed a contrary result compared to other assays. Wanasundara and Shahidi (1995) also assessed the lipid oxidation of canola and soybean oils during storage at $65{ }^{\circ} \mathrm{C}$ for 30 days and found an excellent correlation coefficient with TBA test and CDs. Shahidi et al. (1987) reported that a high correlation was found between the hexanal content and the TBA values in cooked ground pork systems.

With regard to the use of the TBA test, we believe that while absolute values provided by this method are not necessarily reliable due to interferences from other components present in the food, the relative values to be used for comparative purposes show trends that are trustworthy. Hence, the use of this colorimetric assay provides useful information if care is exercised in the use of the methodology. In addition, since MDA is produced when at least 2 or 3 double bonds are present in the molecules, authors using this method for evaluating oxidation of oils when there are no polyunsaturated fatty acids present are cautioned about their misuse of the assay. Finally, mention should be made that when reporting results from the TBA test, results are always reported as TBA reactive substances (TBARS) and as MDA equivalents and not MDA. MDA can only be reported as such when HPLC determination is carried out.

\section{5. $p$-Anisidine and TOTOX value}

$p$-Anisidine value is also one of the classical measurements to test the level of oxidation in animal and vegetable oils. The $p$-anisidine reagent reacts with aldehydes such as 2-alkenal and 2,4-alkedienal under acidic medium, forming yellowish complex that is detectable at $350 \mathrm{~nm}$. In the industry, $p$-anisidine is usually used to calculate TOTOX value, defined as follow:

TOTOX value $=2$ peroxide

value $(\mathrm{PV})+p$-anisidine value $(p-\mathrm{AV})$

This method does not have any real meaning as variables with different units are added. Meanwhile, Wanasundara and Shahidi (1995) proposed the replacement of $p$-anisidine value with TBA value in the calculation of TOTOX and reported the results ad TOTOX-TBA.

\subsection{Fourier transform infrared (FTIR) and Fourier transform Raman spectroscopy}

Fourier transform infrared (FTIR) and Fourier transform Raman spectroscopy have successfully been used for the determination of lipid oxidation. Cebi et al. (2017) employed the attenuated total reflectance (ATR)-Fourier transform infrared spectroscopy (FTIR) to predict the peroxide value of microalgal oil. They monitored the shift of band at $990-940 \mathrm{~cm}^{-1}$, which provides information about the alteration of $\mathrm{C}-\mathrm{H}$ bond from the plane deformation vibration of trans double bond. The results displayed a high relationship with PV. Muik et al. (2005) employed Fourier transform Raman spectroscopy to assess the oxidation of six different vegetable oils. This approach allowed the detection of saturated and $\alpha, \beta$-unsaturated aldehydes formed during lipid oxidation as well as the formation of conjugated double bonds and the isomerisation of cis to trans double bonds in the $\mathrm{C}=\mathrm{C}$ stretching region. Each oil showed a distinct pattern in the spectrum during oxidation, and the results showed a good correlation with other classic oxidation parameters such as p-anisidine value and $\mathrm{K}_{270}$. Guzmán et al. (2011) reported the use of low-resolution Raman spectroscopy to propose a new approach for the analysis of oxidized olive oil. They monitored well-defined bands at $1,267,1,302,1,655$, and $1,747 \mathrm{~cm}^{-1}$ corresponding to symmetric double bond in cis $\delta(=\mathrm{CH})$, in-phase twist methylene, cis double bonds stretching $(\mathrm{C}=\mathrm{C})$, and ester stretching $(\mathrm{C}=\mathrm{O})$, respectively. A high correlation coefficient with other parameters proved the usefulness of low-resolution Raman spectroscopy as a method to assess oxidation of oil/fat along with a simple, non-destructive, analytical procedure. Vaskova and Buckova (2015) investigated the alteration of the chemical structure of edible oils using Raman spectroscopy during the oxidation process. The different Raman peaks such as $1,640,1,658$, and $1,747 \mathrm{~cm}^{-1}$, which accounts for $\mathrm{C}=\mathrm{C}$ double bonds of trans, trans $-2,4$ decadienal, $\mathrm{C}=\mathrm{C}$ cis double bond stretching, and $\mathrm{C}=\mathrm{O}$ ester-carbonyl stretching, respectively, were identified in oxidized canola oil and the method could be used for the prediction of the level of oxidation.

\subsection{Chromatographic techniques for the measurement of lipid oxidation}

Gas-chromatography (GC) is a useful tool to measure volatile compounds generated in lipid oxidation. A major volatile compound in lipid oxidation is hexanal formed from omega- 6 fatty acids such as linoleic, gamma-linolenic, and arachidonic acids by the $\beta$-scission of alkoxyl radical $(\mathrm{RO} \bullet)$, which can be analyzed by using GC with a number of different detectors. Panseri et al. (2011) utilized headspace solid-phase microextraction (HS-SPME) method to isolate volatile compounds from the oxidized butter and injected to the gas chromatography-mass spectrometry (GC/MS) system to analyze hexanal content. CAR/PDMS fibre was used for the extraction of hexanal in samples, and the optimum extraction condition was $180 \mathrm{~min}$ at $4{ }^{\circ} \mathrm{C}$. This approach displayed a great performance in assessing the lipid oxidation of butter by showing a linear increase of hexanal content during the storage of butter for six months. Iglesias et al. (2009) employed SPME-GC/MS to scan volatile compounds in the oxidized minced fish muscle of sea bream and detected 3-hexanone as a major oxidation compound. Chen et al. (2018) investigated the relationship between SPMEGC/MS data and the sensory scores of dairy powders fortified with long-chain polyunsaturated fatty acids and iron. They identified 10 volatile compounds including 1-penten-3-ol, 2-octanone, 3,5-octadien-2-one, decanoic acid, 2-(2-pentenyl) furan, (Z)-4-heptenal, octanoic acid, (E,Z)-2,6-nonadienal, 3-hexanone, and nonanal and concluded that the fishiness of the oxidized samples in sensory test was strongly related with alcohols, ketones, aldehydes, and furans detected in SPME-GC/MS. Oh et al. (2015) measured the level of volatile compounds such as pentane, 2-propenal, hexanal, and trans-2-heptenal during oxidation of linoleic acid in the presence of deuterium oxide using SPME-GC/MS. In addition, Shahidi (2001) reported that propanal was the dominant oxidation product by the breakdown of $\omega-3$ fatty acids such as eicosapentaenoic and docosahexaenoic acids.

Kim et al. (2013) proposed the ratio of saturated fatty acids (SFAs) to unsaturated fatty acids (UFAs) after analysis of GCflame ionization detector (FID) as an efficient means for the evaluation of oxidation of oil/fat. Gas-chromatography (GC) with the different extraction methods and detectors showed an excellent performance in the detection of oxidation products during lipid oxidation.

High performance liquid chromatography (HPLC) is also used for the determination of lipid oxidation of food and biological samples. Jeong et al. (2013) employed 2,4-dinitrophenylhydrazine 
(DNPH) derivatization to detect the oxidation products of lard and linoleic acid before injection to HPLC system. DNPH interacted with aldehydes such as propanal, pentanal, and hexanal produced in lipid oxidation, then the resultant hydrazine complexes were detected by HPLC-UVD at $365 \mathrm{~nm}$. The level of aldehydes-DNPH complex has a high correlation coefficient with DPPH assay to assess lipid oxidation (Lee et al., 2007). Reverse-phase HPLC was also used to quantify malondialdehyde (MDA) content in biological samples after the formation of MDA-TBA complex at $532 \mathrm{~nm}$ (Kosugi et al., 1993). Spirlandeli et al. (2014) investigated the changes in MDA concentration in plasma during exercise using HPLC system. The level of MDA of eight healthy male soccer athletes was significantly increased after exercise. Acrolein was also found in clam (Ruditapes philippinarum) during oil frying as the main oxidation products using HPLC-MS/MS (Liu et al., 2020).

\section{Conclusion}

The use of colorimetric antioxidant screening and lipid oxidation assays have recently been criticized due to their occasionally poor relationship with the results in real biological systems. However, given some attractive advantages of in vitro colorimetric assays such as cost-effectiveness, low variations, lack of inflicting and lack of inflicting pain, distress and death to experimental animals, such assays still provide useful information in certain cases and for comparison of the results upon processing or storage. In this contribution, we discussed detailed principles of various methodologies including in vitro and in vivo antioxidant screening assays and methods for assessing lipid oxidation. The importance of the reconciliation of different methods to complement the advantages and disadvantages of each method is also suggested so that more reasonable conclusions could be reached to address the practical needs in such determinations.

\section{References}

Actis-Goreta, L., Lévèques, A., Giuffrida, F., Romanov-Michailidis, F., Viton, D., Barron, D., Duenas-Paton, M., Gonzalez-Manzano, S., Santos-Buelga, C., Williamson, G., and Dionisi, F. (2012). Elucidation of $(-)$-epicatechin metabolites after ingestion of chocolate by healthy humans. Free Radic. Biol. Med. 53: 787-795.

Adam, A., Crespy, V., Levrat-Verny, M.-A., Leenhardt, F., Leuillet, M., Demigné, C., and Rémésy, C. (2002). The bioavailability of ferulic acid is governed primarily by the food matrix rather than its metabolism in intestine and liver in rats. J. Nutr. 132: 1962-1968.

Ainsworth, E.A., and Gillespie, K.M. (2007). Estimation of total phenolic content and other oxidation substrates in plant tissues using FolinCiocalteu reagent. Nat. Protoc. 2: 875-877.

Alshikh, N., de Camargo, A.C., and Shahidi, F. (2015). Phenolics of selected lentil cultivars: Antioxidant activities and inhibition of low-density lipoprotein and DNA damage. J. Funct. foods. 18: 1022-1038.

Alupului, A., Călinescu, I., and Lavric, V. (2012). Microwave extraction of active principles from medicinal plants. U.P.B. Sci. Bull. Ser. 74: 129142.

Aremu, O.O., Oyedeji, A.O., Oyedeji, O.O., Nkeh-Chungag, B.N., and Rusike, C.R.S. (2019). In vitro and in vivo antioxidant properties of taraxacum officinale in nw-nitro-l-arginine methyl ester (L-NAME)induced hypertensive rats. Antioxidants 8: 309.

Arias, A.M. (2008). Drosophila melanogaster and the development of biology in the 20th century. Methods Mol. Biol. 420: 1-25.

Arnao, M.B. (2000). Some methodological problems in the determination of antioxidant activity using chromogen radicals: A practical case. Trends Food Sci. Technol. 11: 419-421.

Azmir, J., Zaidul, I.S.M., Rahman, M.M., Sharif, K.M., Mohamed, A., Sa- hena, F., Jahurul, M.H.A., Ghafoor, K., Norulaini, N.A.N., and Omar A.K.M. (2013). Techniques for extraction of bioactive compounds from plant materials: A rev. J. Food Eng. 117: 426-436.

Benzie, I.F.F., and Strain, J.J. (1999). Ferric reducing/antioxidant power assay: Direct measure of total antioxidant activity of biological fluids and modified version for simultaneous measurement of total antioxidant power and ascorbic acid concentration. Meth. Enzymol. 299: 15-27.

Blasa, M., Angelino, D., Gennari, L., and Ninfali, P. (2011). The cellular antioxidant activity in red blood cells (CAA-RBC): A new approach to bioavailability and synergy of phytochemicals and botanical extracts. Food Chem. 125: 685-691.

Blois, M.S. (1958). Antioxidant determination by use of a stable free radical. Nat. 181: 1199-1200.

Botas, J. (2007). Drosophila researchers focus on human disease. Natur. Gen. 39: 589-591.

Bozinou, E., Karageorgou, I., Batra, G., Dourtoglou, V.G., and Lalas, S.I. (2019). Pulsed electric field extraction and antioxidant activity determination of Moringa oleifera dry leaves: A comparative study with other extraction techniques. Beverages 5: 8.

Browne, R.W., and Armstrong, D. (2000). HPLC analysis of lipid-derived polyunsaturated fatty acid peroxidation products in oxidatively modified human plasma. Clin Chem. 46: 829-836.

Bryant, G., and Wolfe, J. (1987). Electromechanical stress produced in the plasma membranes of suspended cells by applied electrical fields. J. Membr. Biol. 96: 129-139.

Cadet, J., Delatour, T., Douki, T., Gasparutto, D., Pouget, J.-P., Ravanat, J.L., and Sauvaigo, S. (1999). Hydroxyl radicals and DNA base damage. Mutat. Res. 424: 9-21.

Cañuelo, A., López, B.G., Liñán, P.P., Lara, E.M., Siles, E., and Vizuete, A.M. (2012). Tyrosol, a main phenol present in extra virgin olive oil, increases lifespan and stress resistance in Caenorhabditis elegans. Mech. Ageing Dev. 133: 563-574.

Caro, M., Iturria, I., Martinez-Santos, M., Pardo, M.A., Rainieri, S., Tueros, I., and Navarro, V. (2016). Zebrafish dives into food research: effectiveness assessment of bioactive compounds. Food Funct. 7: 26152623.

Carter, P. (1971). Spectrophotometric determination of serum iron at the submicrogram level with a new reagent (ferrozine). Anal. Biochem. 40: 450-458.

Cebi, N., Yilmaz, M.T., Sagdic, O., Yuce, H., and Yelboga, E. (2017). Prediction of peroxide value in omega-3 rich microalgae oil by ATR-FTIR spectroscopy combined with chemometrics. Food Chem. 225: 188196.

Chandrasekara, A., and Shahidi, F. (2011). Bioactivities and antiradical properties of millet grains and hulls. J. Agric. Food Chem. 59: $9563-$ 9571.

Chemat, F., Rombaut, N., Sicaire, A.G., Meullemiestre, A., Fabiano-Tixier, A.S., and Abert-Vian, M. (2017). Ultrasound assisted extraction of food and natural products. Mechanisms, techniques, combinations, protocols and applications. A review. Ultrason. Sonochem. 34: 540560.

Chen, C., Husny, J., and Rabe, S. (2018). Predicting fishiness off-flavour and identifying compounds of lipid oxidation in dairy powders by SPMEGC/MS and machine learning. Int. Dairy J. 77: 19-28.

Chen, H., Zhang, M., and Xie, B. (2005). Components and antioxidant activity of polysaccharide conjugate from green tea. Food Chem. 90: 17-21.

Chen, Y.H., Yang, Z.S., Wen, C.C., Chang, Y.S., Wang, B.C., Hsiao, C.A., and Shih, T.L. (2012). Evaluation of the structure-activity relationship of flavonoids as antioxidants and toxicants of zebrafish larvae. Food Chem. 134: 717-724.

Chesson, A., Provan, G.J., Russell, W.R., Scobbie, L., Richardson, A.J., and Stewart, C. (1999). Hydroxycinnamic acids in the digestive tract of livestock and humans. J. Sci. Food Agric. 79: 373-378.

Chiremba, C., Rooney, L.W., and Trust, B.J. (2012). Microwave-assisted extraction of bound phenolic acids in bran and flour fractions from sorghum and maize cultivars varying in hardness. J. Chromatogr. A 1012: 119-128.

Corralesa, M., Toepflb, S., Butza, P., Knorrc, D., and Tauschera, B. (2008). Extraction of anthocyanins from grape by-products assisted by ultra- 
sonics, high hydrostatic pressure or pulsed electric fields: a comparison. Innov. Food Sci. Emerg. Technol. 9: 85-91.

Costa Barros-Gomes, J.A., Nascimento, D.L.A., Silveira, A.C.R., Silva, R.K., Gomes, D.L., Melo, K.R.T., Almeida-Lima, J., Camara, R.B.G., Silva, N.B., and Rocha, H.A.O. (2018). In vivo evaluation of the antioxidant activity and protective action of the seaweed Gracilaria birdiae. Oxidative Med. Cell. Longev. 2018: 9354296.

Daker, M., Abdullah, N., Vikineswary, S., Goh, P.C., and Kuppusamy, U.R. (2008). Antioxidant from maize and maize fermented by Marasmiellus sp. as stabiliser of lipid-rich foods. Food Chem. 107: 1092-1098.

Dalton, T.P., Shertzer, H.G., and Puga, A. (1999). Regulation of gene expression by reactive oxygen. Ann. Rev. Pharmacol. Toxicol. 39: 67-101.

Davies, K.J. (2000). Oxidative stress, antioxidant defenses, and damage removal, repair, and replacement systems. IUBMB Life 50: 279-289.

Dawidowicz, A.L., Wianowska, D., and Olszowy, M. (2012). On practical problems in estimation of antioxidant activity of compounds by DPPH method. Food Chem. 131: 1037-1043.

Delsart, C., Ghidossi, R., Poupot, C., Cholet, C., Grimi, N., Vorobiev, E., Milisic, V., and Peuchot, M.M. (2012). Enhanced extraction of phenolic compounds from merlot grapes by pulsed electric field treatment. Am. J. Enol. Viticult. 63: 205-211.

Dhobi, M., Mandal, V., and Hemalatha, S. (2009). Optimization of microwave assisted extraction of bioactive flavolignan-silybinin. J. Chem. Metrol. 3: 13-23.

Erdogan, S., Ates, B., Durmaz, G., Yilmaz, I., and Seckin, T. (2011). Pressurized liquid extraction of phenolic compounds from Anatolia propolis and their radical scavenging capacities. Food Chem. Toxicol. 49 1592-1597.

Garcia-Salas, P., Morales-Soto, A., Segura-Carretero, A., and FernándezGutiérrez, A. (2010). Phenolic-compound-extraction systems for fruit and vegetable samples. Molecules 15: 8813-8826.

Giannuzzo, A.N., Boggetti, H.J., Nazareno, M.A., and Mishima, H.T. (2003). Supercritical fluid extraction of naringin from the peel of citrus paradise. Phytochem. Analysis 14: 221-223.

Guderjan, M., Töpfl, S., Angersbach, A., and Knorr, D. (2005). Impact of pulsed electric field treatment on the recovery and quality of plant oils. J. Food Eng. 67: 281-287.

Gutierrez, E., Wiggins, D., Fielding, B., and Gould, A.P. (2007). Specialized hepatocyte-like cells regulate Drosophila lipid metabolism. Nature 445: 275-280.

Guzmán, E., Baeten, V., Pierna, J.A.F., and García-Mesa, J.A. (2011). Application of low-resolution Raman spectroscopy for the analysis of oxidized olive oil. Food Con. 22: 2036-2040.

Halliwell, B. (1997). Antioxidants in human health and disease. Ann. Rev. Nutr. 16: 33-50.

Harnly, J. (2017). Antioxidant methods. J. Food Comp. Anal. 64: 145-146.

Hawthorne, S.B., Yang, Y., and Miller, D.J. (1994). Extraction of organic pollutants from environmental solids with sub- and supercritical water Anal. Chem. 66: 2912-2920

Heinz, V., Toepfl, S., and Knorr, D. (2003). Impact of temperature on lethality and energy efficiency of apple juice pasteurization by pulsed electric fields treatment. Innov. Food Sci. Emerg. Technol. 4: 167-175.

Herrera, M.C., and Luque de Castro, M.D. (2005). Ultrasound-assisted extraction of phenolic compounds from strawberries prior to liquid chromatographic separation and photodiode array ultraviolet detection. J. Chromatogr. 1100: 1-7.

Huang, D., Ou, B., and Prior, R.L. (2005). The chemistry behind antioxidant capacity assays. J. Agric. Food Chem. 53: 1841-1856.

Huangfu, J., Liu, J., Sun, Z., Wang, M., Jiang, Y., Chen, Z.Y., and Chen, F. (2013). Antiaging effects of astaxanthin-rich alga Haematococcus pluvialis on fruit flies under oxidative stress. J. Agric. Food Chem. 61 7800-7804.

Ibañez, E., Herrero, M., Mendiola, J.A., and Castro-Puyana, M. (2012). Extraction and characterization of bioactive compounds with health benefits from marine resources: macro and micro algae, cyanobacteria, and invertebrates. In: Hayes, M. (Ed.). Marine Bioactive Compounds: Sources, Characterization and Applications. Springer, Berlin, pp. 55-98.

Iglesias, J., Medina, I., Bianchi, F., Careri, M., Mangia, A., and Musci, M. (2009). Study of the volatile compounds useful for the characterisation of fresh and frozen thawed cultured gilthead sea bream fish by solid-phase microextraction gas chromatography-mass spectrometry. Food Chem. 115: 1473-1478.

Inczedy, J., Lengyel, T., and Ure, A.M. (1998). Supercritical Fluid Chromatography and Extraction. Compendium of analytical nomenclature: definitive rules 1997. 3rd ed. Blackwell Science.

Ishikado, A., Sono, Y., Matsumoto, M., Stacey, R.S., Aya, O., Masashi, G., George, L.K., Blackwell, T.K., and Taketoshi, M. (2013). Willow bark extract increases antioxidant enzymes and reduces oxidative stress through activation of Nrf2 in vascular endothelial cells and Caenorhabditis elegans. Free Radic. Biol. Med. 65: 1506-1515.

Jain, T. (2009). Microwave assisted extraction for phytoconstituents - an overview. Asian J. Res. Chem. 2: 19-25.

Jeong, M.K., Yeo, J.D., Jang, E.Y., and Lee, J.H. (2013). Monitoring of radical scavenging compounds from oxidized lipids (RSOL) by 2,4-dinitrophenylhydrazine (DNPH) derivatization in thermally oxidized linoleic acid and lard systems. Food Sci. Biotechnol. 22: 161-165.

Jones, D.P. (2006). Redefining oxidative stress. Antioxid. Redox Sign. 8: 1865-1879.

Karakaya, S. (2004). Bioavailability of phenolic compounds, critical reviews. Food Sci. Nutr. 44: 453-464

Kellett, M.E., Greenspanb, P., and Pegg, R.B. (2018). Modification of the cellular antioxidant activity (CAA) assay to study phenolic antioxidants in a Caco-2 cell line. Food Chem. 244: 359-363.

Khorassani, M.A., and Taylor, L.T. (2004). Sequential fractionation of grape seeds into oils, polyphenols, and procyanidins via a single system employing CO2-based fluids. J. Agric. Food Chem. 52: 2440-2444.

Kim, J.Y., Hong, J.H., Jung, H.K., Jeong, Y.S., and Cho, K.H. (2012). Grape skin and loquat leaf extracts and acai puree have potent anti-atherosclerotic and anti-diabetic activity in vitro and in vivo in hypercholesterolemic zebrafish. Int. J. Mol. Med. 30: 606-614.

Kim, T.S., Yeo, J.D., Kim, J.Y., Kim, M.J., and Lee, J.H. (2013). Determination of the degree of oxidation in highly-oxidised lipids using profile changes of fatty acids. Food Chem. 138: 1792-1799.

Kim, Y.S., Hwang, J.W., Sung, S.H., Jeon, Y.J., Jeong, J.H., Jeon, B.T., Moon, S.H., and Park, P.J. (2015). Antioxidant activity and protective effect of extract of Celosia cristata L.flower on tert-butyl hydroperoxideinduced oxidative hepatotoxicity. Food Chem. 168: 572-579.

Kinth, P., Mahesh, G., and Panwar, Y. (2013). Mapping of zebrafish research: A global outlook. Zebrafish 10: 510-517.

Kirkwood, J.S., Lebold, K.M., Miranda, C.L., Wright, C.L., Miller, G.W., Tanguay, R.L., Barton, C.L., Traber, M.G., and Stevens, J.F. (2012). Vitamin $\mathrm{C}$ deficiency activates the purine nucleotide cycle in zebrafish. J. Biol. Chem. 287: 3833-3841.

Klejdusa, B., Kopecký, J., Benesová, L., and Vaceka, J. (2009). Solid-phase/ supercritical-fluid extraction for liquid chromatography of phenolic compounds in freshwater microalgae and selected cyanobacterial species. J. Chromatogr. A. 1216: 763-771.

Kosugi, H., Kojima, T., and Kikugawa, K. (1993). Characteristics of the thiobarbituric acid reactivity of human urine as a possible consequence of lipid peroxidation. Lipids 28: 337-343.

Kruidenier, L., and Verspaget, H.W. (2012). Review article: Oxidative stress as a pathogenic factor in inflammatory bowel disease -Radicals or ridiculous? Alim. Pharm. Therap. 16: 1997-2015.

Lee, J.M., Chung, H., Chang, P.S., and Lee, J.H. (2007). Development of a method predicting the oxidative stability of edible oils using 2,2-diphenyl-1-picrylhydrazyl (DPPH). Food Chem. 103: 662-669.

Liao, V.H., Yu, C.W., Chu, Y.J., Li, W.H., Hsieh, Y.C., and Wang, T.T. (2011) Curcumin-mediated lifespan extension in Caenorhabditis elegans. Mech. Ageing Dev. 132: 480-487.

Lin, L.Z., Yang, K., Zheng, L., Zhao, M.M., Sun, W.Z., Zhu, Q.Y., and Liu, S.J. (2018). Anti-aging effect of sea cucumber (Cucumaria frondosa) hydrolysate on fruit flies and D-galactose-induced aging mice. J. Funct. Foods 47: 11-18.

Liu, R.H. (2003). Health benefits of fruits and vegetables are from additive and synergistic combinations of phytochemicals. Amer. J. Clin. Nutr. 78: 517-520.

Liu, Z., Esveld, E., Vincken, J.P., and Bruins, M.E. (2019). Pulsed electric field as an alternative pre-treatment for drying to enhance polyphenol extraction from fresh tea leaves. Food Biopr. Technol. 12: 183-192.

Liu, Z.W., Zeng, X.A., and Ngadi, M. (2018). Enhanced extraction of phenolic compounds from onion by pulsed electric field (PEF). J. Food 
Process. Preserv. 42: e13755.

Liu, Z.Y., Zhou, D.Y., Li, A., Zhao, M.T., Hu, Y.Y., Li, D.Y., Xie, H.K., Zhao, Q., $\mathrm{Hu}$, X.P., Zhang, J.H., and Shahidi, F. (2020). Effects of temperature and heating time on the formation of aldehydes during the frying process of clam assessed by an HPLC-MS/MS method. Food Chem. 308: 125650 .

Lovrić, V., Putnik, P., Kovačević, D.B., Jukić, M., and Dragović-Uzelac, V. (2017). Effect of microwave-assisted extraction on the phenolic compounds and antioxidant capacity of blackthorn flowers. Food Technol. Biotechnol. 55: 243-250.

Luo, S., Jiang, X., Jia, L., Tan, C., Li, M., Yang, Q., Du, Y., and Ding, C. (2019). In vivo and in vitro antioxidant activities of methanol extracts from olive leaves on Caenorhabditis elegans. Molecules 24: 704.

Luo, Y., Peng, B., Wei, W., Tian, X., and Wu, Z. (2019). Antioxidant and antidiabetic activities of polysaccharides from guava leaves. Molecules 24: 1343.

Luthria, D.L. (2008). Influence of experimental conditions on the extraction of phenolic compounds from parsley (Petroselinum crispum) flakes using a pressurized liquid extractor. Food Chem. 107: 745-752.

Lyras, L., Cairns, N.J., Jenner, A., and Jenner, P. (1997). An assessment of oxidative damage to proteins, lipids, and DNA in brain from patients with Alzheimer's disease. Neurochem. 68: 2061-2069.

Madhujith, T., and Shahidi, F. (2007). Antioxidative and antiproliferative properties of selected barley (Hordeum vulgarae L.) cultivars and their potential for inhibition of low density lipoprotein (LDL) cholesterol oxidation. J. Agric. Food Chem. 55: 5018-5024.

McGowan, J.C., Powell, T., and Raw, R. (1959). The rates of reaction of $\alpha, \alpha$-diphenyl- $\beta$-picrylhydrazyl with certain amines and phenols. J. Chem. Soc. 3103-3110.

Miller, N.J., Rice-Evans, C., Davies, M.J., Gopinathan, V., and Milner, A. (1993). A novel method for measuring antioxidant capacity and its application to monitoring the antioxidant status in premature neonates. Clin. Sci. 84: 407-412.

Morales, A., Marmesat, S., Ruiz-Méndez, M.V., Márquez-Ruiz, G., and Velasco, J. (2014). Formation of oxidation products in edible vegetable oils analyzed as FAME derivatives by HPLC-UV-ELSD. Food Res. Int. 62: 1080-1086.

Muik, B., Lendl, B., Molina-Díaz, A., and Ayora-Cañada, M.J. (2005). Direct monitoring of lipid oxidation in edible oils by fourier transform raman spectroscopy. Chem. Phys. Lip. 134: 173-182.

Mullen, W., Edwards, C.A., and Crozier, A. (2006). Absorption, excretion and metabolite profiling of methyl-, glucuronyl-, glucosyl- and sulpho-conjugates of quercetin in human plasma and urine after ingestion of onions. Br. J. Nut. 96: 107-116.

Naithani, V., Nair, S., and Kakkar, P. (2006). Decline in antioxidant capacity of Indian herbal teas during storage and its relation to phenolic content. Food Res. Int. 39: 176-181.

Nieto, A., Borrull, F., Pocurull, E., and Marcé, R.M. (2010). Pressurized liquid extraction: a useful technique to extract pharmaceuticals and personal-care products from sewage sludge. TRAC-Trend. Anal. Chem. 29: 752-764.

Oh, S., Yi, B.R., Kim, M.J., and Lee, J.H. (2015). Effects of deuterium oxide on formation of volatiles in linoleic acid model systems at different temperatures and oxygen limitation conditions. Food Sci. Biotechnol. 24: 41-46.

Ottaviani, J.I., Momma, T.Y., Kuhnle, G.K., Keen, C.L., and Schroeter, H. (2012). Structurally related (-)-epicatechin metabolites in humans: Assessment using de novo chemically synthesized authentic standards. Free Radic. Biol. Med. 52: 1403-1412.

Pan, X., Niu, G., and Liu, H. (2003). Microwave-assisted extraction of tea polyphenols and tea caffeine from green tea leaves. Chem. Eng. Process. 42: 129-133.

Panseri, S., Soncin, S., Chiesa, L.M., and Biondi, P.A. (2011). A headspace solid-phase microextraction gas-chromatographic mass-spectrometric method (HS-SPME-GC/MS) to quantify hexanal in butter during storage as marker of lipid oxidation. Food Chem. 127: 886-889.

Papariello, G.J., and Janish, M.A.M. (1966). Diphenylpicrylhydrazyl as an organic analytical reagent in the spectrophotometric analysis of phenols. Anal. Chem. 38: 211-214.

Peña-Ramos, E.A., and Xiong, Y.L. (2003). Whey and soy protein hydrolysates inhibit lipid oxidation in cooked pork patties. Meat Sci. 64:
259-263.

Prior, R.L. (2012). Anthocyanins: Understanding their absorption and metabolism. In: Spencer, J.P.E., and Crozier, A. (Ed.). Flavonoids and related compounds. Bioavailability and function CRC Press, Boca Raton, pp. 79-92.

Rojanasakul, Y., Wang, L., Hoffman, A.H., Shi, X., Dalal, N.S., Banks, D.E., and Ma, J.K. (1993). Mechanisms of hydroxyl free radical-induced cellular injury and calcium overloading in alveolar macrophages. Am. J. Respir. Cell Mol. Biol. 8: 377-383.

Rostagno, M.A., Palma, M., and Barroso, C.G. (2004). Pressurized liquid extraction of isoflavones from soybeans. Anal. Chim. Acta 522: 169177.

Roy, J.K., Juneja, L.R., Isobe, S., and Tsushida, T. (2009). Steam processed broccoli (Brassica oleracea) has higher antioxidant activity in chemical and cellular assay systems. Food Chem. 114: 263-269.

Saldaña, M.D.A., Mohamed, R.S., Baer, M.G., and Mazzafera, P. (1999). Extraction of purine alkaloids from maté (Ilex paraguariensis) using supercritical CO2. J. Agric. Food Chem. 47: 3804-3808.

Sánchez-Moreno, C. (2002). Review: methods used to evaluate the free radical scavenging activity in foods and biological systems. Food Sci. Technol. Int. 8: 121-137.

Schaich, K.M. (2005). Lipid oxidation: Theoretical aspect. In: Shahidi, F. (Ed.). Bailey's industrial oil and fat products (6th ed.). John Wiley \& Sons Inc., Hoboken, pp. 269-355.

Sessa, M., Tsao, R., Liu, R., Ferrari, G., and Donsi, F. (2011). Evaluation of the stability and antioxidant activity of nanoencapsulated resveratrol during in vitro digestion. J. Agric. Food Chem. 59: 12352-12360.

Setyaningsih, W., Saputro, E., Palm, M., and Barroso, C.G. (2016). Pressurized liquid extraction of phenolic compounds from rice (Oryza sativa) grains. Food Chem. 192: 452-459.

Shahidi, F. (2001). Headspace volatile aldehydes as indicators of lipid oxidation in foods. Ad. Exp. Med. Biol. 488: 113-123.

Shahidi, F., and Yeo, J.D. (2018). Bioactivities of phenolics by focusing on suppression of chronic diseases: A review. Int. J. Mol. Sci. 19: 1573.

Shahidi, F., and Zhong, Y. (2010). Lipid oxidation and improving the oxidative stability. Chem. Soc. Rev. 39: 4067-4079.

Shahidi, F., and Zhong, Y. (2015). Measurement of antioxidant activity. J. Funct. Foods 18: 757-781.

Shahidi, F., Yun, J., Rubin, L.J., and Wood, D.F. (1987). The hexanal content as an indicator of oxidative stability and flavour acceptability in cooked ground pork. Can. Inst. Food Sci. Technol. J. 20: 104-106.

Shen, P., Yue, Y., Zheng, J., and Park, Y. (2017). Caenorhabditis elegans: A convenient in vivo model for assessing the impact of food bioactive components on obesity, aging, and alzheimer's disease. Annu. Rev. Food Sci. Technol. 9: 1-22.

Shih, T.L., Hsiao, C.A., Lin, Z.Y., and Chen, Y.H. (2012). An alternative synthesis of 3',4'-diaminoflavones to evaluate their antioxidant ability and cell apoptosis of zebrafish larvae. Molecules 17: 8206-8216.

Sihvonen, M., Järvenpää, E., Hietaniemi, V., and Huopalahti, R. (1999). Advances in supercritical carbon dioxide technologies. Trend. Food Sci. Technol. 10: 217-222.

Singh, S., Kaur, M., Sogi, D.S., and Purewal, S.S. (2019). A comparative study of phytochemicals, antioxidant potential and in-vitro DNA damage protection activity of different oat (Avena sativa) cultivars from India. J. Food Meas. Charact. 13: 347-356.

Singleton, V.L., Orthofer, R., and Lamuela-Raventos, R.M. (1999). Analysis of total phenols and other oxidation substrates and antioxidants by means of Folin-Ciocalteu reagent. Meth. Enzymol. 299: 152-178.

Song, W., Derito, C.M., Liu, K.M., He, X., Dong, M., and Liu, R.H. (2010). Cellular antioxidant activity of common vegetables. J. Agric. Food Chem. 58: 6621-6629.

Spirlandeli, A.L., Deminice, R., and Jordao, A.A. (2014). Plasma malondialdehyde as biomarker of lipid peroxidation: Effects of acute exercise. Int. J. Sports Med. 35: 14-18.

Vaskova, H., and Buckova, M. (2015). Thermal degradation of vegetable oils: Spectroscopic measurement and analysis. Proc. Eng. 100: 630-635.

Verma, A., Hartonen, K., and Riekkola, M.L. (2008). Optimisation of supercritical fluid extraction of indole alkaloids from Catharanthus roseus using experimental designmethodology-comparison with other extraction techniques. Phytochem. Analysis 19: 52-63.

Vilkhu, K., Mawson, R., Simons, L., and Bates, D. (2008). Applications and 
opportunities for ultrasound assisted extraction in the food industry Innov. Food Sci. Emerg. 9: 161-169.

Wanasundara, U.N., and Shahidi, F. (1995). Storage stability of microcapsulated seal blubber oil. J. Food lipids 2: 73-86.

Wang, H., and Joseph, J.A. (1999). Quantifying cellular oxidative stress by dichlorofluorescein assay using microplate reader. Free Radic. Biol. Med. 27: 612-616.

Wassef, R., Haenold, R., Hansel, A., Brot, N., Heinemann, S.H., and Hoshi, T. (2007). Methionine sulfoxide reductase $A$ and a dietary supplement S-methyl-L-cysteine prevent Parkinson's-like symptoms. J. Neurosci. 27: 12808-12816.

Wolfe, K.L., and Liu, R.H. (2007). Cellular antioxidant activity (CAA) assay for assessing antioxidants, foods, and dietary supplements. J. Agric. Food Chem. 55: 8896-8907.

Wolfe, K.L., Kang, X., He, X., Dong, M., Zhang, Q., and Liu, R.H. (2008). Cellular antioxidant activity of common fruits. J. Agric. Food Chem. 56: 8418-8426.

Wolffram, S., Weber, T., Grenacher, B., and Scharrer, E. (1995). A Na+-dependent mechanism is involved in mucosal uptake of cinnamic acid across the jejunal brush border in rats. J. Nutr. 125: 1300-1308.

$\mathrm{Xu}$, B., and Chang, S.K. (2010). Phenolic Substance characterization and chemical and cell-based antioxidant activities of 11 lentils grown in the Northern United States. J. Agric. Food Chem. 58: 1509-1517.

Yang, H.M., Ham, Y.M., Yoon, W.J., Roh, S.W., Jeon, Y.J., Oda, T., Kang, S.M., Kang, M.C., Kim, E.A., Kim, D., and Kim, K.N. (2012). Quercitrin protects against ultraviolet B-induced cell death in vitro and in an in vivo zebrafish model. J. Photochem. Photobiol. B 114: 126-131.

Yang, L., Wang, H., Yuan-gang, Z.u., Zhao, C., Zhang, L., Chen, X., and Zhang, Z. (2011). Ultrasound-assisted extraction of the three terpenoid indole alkaloids vindoline, catharanthine and vinblastine from Catharanthus roseus using ionic liquid aqueous solutions. Chem. Eng. 172: 705-712.

Yeo, J.D., and Shahidi, F. (2019a). Revisiting DPPH (2,2-diphenyl-1-picrylhydrazyl) assay as a useful tool in antioxidant evaluation: a new IC100 concept to address its limitations. J. Food Bioact. 7: 36-42.

Yeo, J.D., and Shahidi, F. (2020). Identification and quantification of soluble and insoluble-bound phenolics in lentil hulls using HPLC-ESI-MS/MS and their antioxidant potential. Food Chem. 315: 126202

Yeo, J.D., and Shahidi, F. (2019b). Critical re-evaluation of DPPH assay:
Presence of pigments affects the results. J. Agric. Food Chem. 67 7526-7529.

Yeo, J.D., Park, J.W., and Lee, J.H. (2011). Evaluation of antioxidant capacity of sesamol in lard model systems with different oxidation temperature. Eur. J. Lipid Sci. Technol. 113: 910-915.

Zeb, A. (2012). Triacylglycerols composition, oxidation and oxidation compounds in camellia oil using liquid chromatography-mass spectrometry. Chem. Phys. Lipids 165: 608-614.

Zhang, H., Yin, M., Huang, L., Wang, J., Gong, L., Liu, J., and Sun, B. (2017) Evaluation of the cellular and animal models for the study of antioxidant activity: A review. J. Food Sci. 82: 278-288.

Zhang, Y., Mi, D.Y., Wang, J., Luo, Y.P., Yang, X., Dong, S., Ma, X.M., and Dong, Z. (2018). Constituent and effects of polysaccharides isolated from Sophora moorcroftiana, seeds on lifespan, reproduction, stress resistance, and antimicrobial capacity in Caenorhabditis elegans. Chin. J. Nat. Med. 16: 252-260.

Zhong, Y., and Shahidi, F. (2012). Lipophilized epigallocatechin gallate (EGCG) derivatives and their antioxidant potential in food and biological systems. Food Chem. 131: 22-30.

Zhou, X., Zhou, D.-Y., Liu, Z.-Y., Yin, F.-W., Liu, Z.-Q., Li, D.-Y., and Shahidi, F. (2019). Hydrolysis and oxidation of lipids in mussel Mytilus edulis during cold storage. Food Chem. 272: 109-116.

Ziberna, L., Lunder, M., Moze, S., Vanzo, A., Tramer, F., Passamonti, S., and Drevensek, G. (2010). Acute cardioprotective and cardiotoxic effects of bilberry anthocyanins in ischemia-reperfusion injury: Beyond concentration-dependent antioxidant activity. Cardiovasc. Toxicol. 10: $283-294$.

Zosel, K. (1964). Method for separation of mixtures. German Patent 1493:190.

Zou, Y.X., Ruan, M.H., Luan, J., Feng, X., Chen, S., and Chu, Z.-Y. (2017). Anti-aging effect of riboflavin via endogenous antioxidant in fruit fly Drosophila melanogaster. J. Nutr. Health Aging 21: 314-319.

Zougagh, M., Valcárcel, M., and Ríos, A. (2004). Supercritical fluid extraction: A critical review of its analytical usefulness. TRAC-Trend. Anal. Chem. 23: 399-405.

Zu, G., Zhang, R., Yang, L., Ma, C., Zu, Y., Wang, W., and Zhao, C. (2012). Ultrasoundassisted extraction of carnosic acid and rosmarinic acid using ionic liquid solution from Rosmarinus officinalis. Int. J. Mol. Sci. 13: 11027-11043. 